\title{
Fatores Críticos de Sucesso para Melhoria de Processos de Serviços de TI: Um Mapeamento Sistemático
}

\author{
Thaíssa Diirr, Gleison Santos \\ Programa de Pós-Graduação em Informática - Universidade Federal do Estado do Rio \\ de Janeiro (UNIRIO) - Av. Pasteur 458, Urca, CEP 22290-240 - Rio de Janeiro, RJ \\ \{thaissa.medeiros, gleison.santos\}@uniriotec.br
}

\begin{abstract}
Models for maturity and management of IT services guide the improvement of IT services management processes. Known approaches include ITIL, COBIT, ISO/IEC 20.000, CMMI-SVC and MR-MPS-SV. The implementation of these models results in benefits, but there are organizations that face difficulties. This paper presents a systematic mapping study in order to identify critical factors of success and of failure for IT services processes improvement. Some identified factors were: project implementation strategy; support, commitment and involvement; resources and processes. The results were correlated using Grounded Theory procedures to facilitate analysis.
\end{abstract}

Resumo. Modelos para maturidade e gestão de serviços de TI orientam a melhoria de processos de gerenciamento de serviços de TI. Abordagens já conhecidas incluem ITIL, COBIT, ISO/IEC 20.000, CMMI-SVC e MR-MPS$S V$. A implantação desses modelos resulta em benefícios, mas há organizações que enfrentam dificuldades. Este artigo apresenta um mapeamento sistemático da literatura, a fim de identificar fatores críticos de sucesso e de fracasso para a melhoria de processos de serviços de TI. Alguns fatores encontrados foram: estratégia de implementação do projeto; apoio, comprometimento e envolvimento; recursos e processos. Os resultados obtidos foram relacionados utilizando procedimentos da Grounded Theory de forma a facilitar a análise.

\section{Introdução}

Um serviço é um meio de entregar valor aos clientes, facilitando o resultado que querem alcançar sem arcar com riscos e custos específicos (SEI, 2010; Cartlidge et al., 2007). Um serviço de Tecnologia da Informação (TI) é um conjunto de recursos, TI e não-TI, percebidos pelo cliente como um todo coerente e mantidos por um provedor de TI, a fim de atender uma ou mais necessidades de um cliente e apoiar os objetivos estratégicos do seu negócio (Magalhães e Brito, 2007).

Para alcançar bom desempenho do provedor de serviços e satisfação do cliente, é necessário o desenvolvimento e melhoria das práticas de serviços (SEI, 2010). Nesse contexto, modelos de maturidade e gestão de serviços de TI foram propostos e orientam as organizações na definição e melhoria de processos de gerenciamento de serviços. Abordagens já conhecidas e difundidas incluem: ITIL (Cartlidge et al., 2007), COBIT (ITGI, 2007), ISO/IEC 20.000 (ISO, 2009, 2010a, 2010b, 2011, 2012), CMMI-SVC (SEI, 2010) e MR-MPS-SV (SOFTEX, 2012).

Uma série de benefícios é apontada como consequência da implantação desses modelos (SEI, 2010; Cartlidge et al., 20007 e ITGI, 2007): aumento da satisfação de clientes e usuários com os serviços, maior produtividade, economia financeira com re- 
dução de trabalho e melhoria na utilização e gerenciamento de recursos, melhoria da tomada de decisão, maior disponibilidade dos serviços, maior alinhamento da TI aos objetivos de negócio, gerência apropriada dos riscos de TI, divisão clara das responsabilidades, entre outros. Porém, há organizações que enfrentam dificuldades durante projetos de implementação de melhorias em processos de serviços de TI e não obtém sucesso (Jäntti, 2010; Pollard e Cater-Steel, 2009; Sharifi et al., 2008).

Alguns fatores, chamados Fatores Críticos de Sucesso, influenciam e contribuem para o sucesso do projeto de implementação de melhorias no gerenciamento de serviços de TI, conforme apontado por Tan et al. (2007, 2009) e Pollard e Cater-Steel (2009). Fatores Críticos de Sucesso são áreas chave que precisam dar certo para que o negócio prospere e, se não forem bem realizadas, é improvável que a missão, objetivos ou metas de um negócio ou projeto sejam atingidos (Rockart, 1979 apud Pollard e Cater-Steel, 2009). Em contrapartida, Fatores Críticos de Fracasso ou Fatores de Risco podem colocar em risco e resultar na falha da implementação de melhoria de processos de serviços de TI (Ghayekhloo et al., 2009; Wan et al., 2008). Montoni (2010) identificou fatores críticos de sucesso para implementação de processos de software a partir da execução de um mapeamento sistemático da literatura. Não entanto, não foi possível verificar, ainda, o mesmo trabalho feito no contexto de serviços de TI.

Dessa forma, o objetivo deste artigo é identificar fatores críticos de sucesso e de fracasso em iniciativas de melhoria de processos no contexto de serviços de TI, a fim de servir como aprendizado e auxiliar organizações que desejam melhorar seus processos de serviços de TI a elaborarem estratégias de implementação com maior possibilidade de alcançar sucesso.

Além desta introdução, este artigo apresenta ainda 5 seções. A Seção 2 apresenta um breve referencial teórico sobre melhoria de processos de serviços de TI. A Seção 3 descreve o protocolo do mapeamento sistemático realizado e a Seção 3 discorre sobre os resultados. Na Seção 5 apresentada uma comparação com fatores críticos em melhoria de processos de software e a Seção 6 descreve as considerações finais do trabalho.

\section{Melhoria de Processos de Serviços de TI}

Uma organização dependente dos serviços de TI para continuidade dos seus negócios pode perder de milhares a milhões de dólares de receita por hora de interrupção em um serviço de TI, processos críticos podem ser interrompidos, a imagem e as ações da corporação podem ser danificadas (Magalhães e Brito, 2007; Ghayekhloo et al., 2009). Assim, quanto mais as organizações se tornam dependentes de tecnologia, a necessidade de serviços confiáveis e bem administrados aumenta (Ghayekhloo et al., 2009).

A governança de serviços de TI busca evitar a ocorrência de problemas na entrega e operação dos serviços prestados, a fim de que sua qualidade seja percebida por clientes e usuários (Magalhães e Brito, 2007). Nesse contexto, modelos de maturidade e gestão de serviços de TI foram propostos e incluem as seguintes abordagens já conhecidas e difundidas: ITIL, COBIT, ISO/IEC 20.000, CMMI-SVC e MR-MPS-SV.

ITIL (Information Technology Infrastructure Library) é um framework de melhores práticas para gerenciamento de serviços de TI, composto de cinco livros que cobrem o ciclo de vida do serviço. O livro Estratégia de Serviço fornece orientações aos provedores de serviços na construção de uma estratégia clara para operar e prosperar em longo prazo. O Projeto de Serviço projeta serviços de TI inovadores e apropriados para 
atender a exigências de negócio atuais e futuras. A Transição de Serviço entrega os serviços para uso operacional e a Operação de Serviço entrega os níveis acordados de serviços para usuários e clientes. Por fim, a Melhoria Contínua de Serviços avalia e melhora continuamente a qualidade de serviços e a maturidade do seu ciclo de vida e de processos subjacentes (Cartlidge et al., 2007).

COBIT (Control Objectives for Information and related Technology) é um framework mais amplo que fornece boas práticas para governança de TI e descreve um conjunto de objetivos de negócio e um conjunto objetivos de TI relacionados (ITGI, 2007; Barreto e Rocha, 2009). As atividades são definidas em um modelo de processos genéricos divididos em quatro domínios. O domínio Planejar e Organizar direciona a entrega de soluções e de serviços, identificando a maneira que a TI pode contribuir para atingir os objetivos de negócios. Adquirir e Implementar provê as soluções e as transfere para tornarem-se serviços e Entregar e Suportar recebe as soluções e torna-as passíveis de uso pelos usuários finais. Finalmente, o domínio Monitorar e Avaliar monitora todos os processos para garantir que a direção definida seja seguida (ITGI, 2007).

ISO/IEC 20.000 é uma norma para gerenciamento de serviços de TI que consiste em cinco partes. A ISO/IEC 20.000-1 especifica requisitos para o provedor de serviços implantar um sistema de gerenciamento de serviços (ISO, 2011). Já a ISO/IEC 20.000-2 consiste de práticas para aplicação desses requisitos, a ISO/IEC TR 20.000-3 fornece orientações para definir escopo e aplicabilidade do sistema de gestão de serviços e a ISO/IEC TR 20.000-5 apresenta um exemplo de plano de implementação em fases (ISO, 2012, 2009, 2010b). Por fim, a ISO/IEC TR 20.000-4 descreve um modelo de referência de processos para gerenciamento de serviços derivados dos requisitos da parte 1 (ISO, 2010a).

CMMI-SVC (Capability Maturity Model for Services) é um modelo de maturidade voltado para empresas fornecedoras de serviços. Dois caminhos incrementais são possíveis para a melhoria dos processos: contínuo (melhoria de um processo individual ou grupo de processos escolhidos pela organização) ou por estágios (melhoria de um conjunto de processos relacionados já definidos pelo modelo). A representação contínua permite atingir níveis de capacidade de cada processo escolhido, que variam do 0 ao 3. Já a representação por estágios permite a obtenção de níveis de maturidade evolucionários para a organização, que variam do 1 ao 5 (SEI, 2010).

MR-MPS-SV (Modelo de Referência de Melhoria de Processos de Software e Serviços - para Serviços) também é um modelo de maturidade voltado para empresas fornecedoras de serviços de TI, mas possui foco em micro, pequenas e médias empresas. A capacidade dos processos é representada por conjunto de atributos de processo (até nove no total), atendidos quando seus resultados esperados são atingidos. Já os níveis de maturidade são sete, progredindo do G ao A (SOFTEX, 2012).

\section{Protocolo do Mapeamento Sistemático}

O objetivo deste mapeamento sistemático é analisar relatos de iniciativas de melhoria em organizações que fornecem serviços de TI, com o propósito de identificar e analisar fatores críticos de sucesso e de fracasso, com relação à influência no sucesso ou no fracasso das iniciativas de melhoria de processos de serviços de TI, do ponto de vista de organizações que implementam melhoria em processos de serviços de TI e profissionais de TI envolvidos nas iniciativas e no contexto de empresas fornecedoras de servi- 
ços de TI implementando melhorias nos seus processos de serviços de TI.

Duas questões de pesquisa foram definidas para alcançar o objetivo descrito:

- Q1 - Quais fatores exercem influência positiva nas iniciativas de melhoria de processos de serviços de TI?

- Q2 - Quais fatores exercem influência negativa nas iniciativas de melhoria de processos de serviços de TI?

Em relação ao escopo da pesquisa, os critérios adotados para selecionar as fontes de busca foram: pertencer a uma das editoras listadas no Portal de Periódicos da CAPES ou ser um evento relacionado à Engenharia de Software apoiado pela SBC (Sociedade Brasileira de Computação); e possuir relação com o tema a ser pesquisado. A pesquisa se restringe à análise de publicações disponíveis até a data presente da execução do estudo. Os idiomas escolhidos foram o inglês (devido à sua adoção pela maioria das conferências, periódicos e editoras da área de pesquisa) e o português (para incluir trabalhos técnicos publicados em conferências nacionais).

Foram selecionadas as bibliotecas digitais Compendex e Scopus que possuem máquinas de busca com bom funcionamento e abrangência, além das conferências nacionais SBQS (Simpósio Brasileiro de Qualidade de Software) e WAMPS (Workshop Anual do MPS).

A expressão de busca utilizada foi: (itil OR cobit OR "iso/iec 20000" OR cmmisvc OR mps-sv OR "it service management" OR "gestão de serviços de ti") AND (implementation OR implantação OR "process improvement" OR "melhoria de processo") $A N D$ (factor OR fator OR factors OR fatores OR strategy OR estratégia OR strategies OR estratégias). O primeiro conjunto de termos da expressão compreende os modelos de serviços de TI descritos na Seção 2, além do termo "IT service management" ou "gestão de serviços de TI" para atender a publicações que não mencionam especificamente um desses modelos ou utilizam outros modelos particulares. $\mathrm{O}$ segundo conjunto de termos restringe o resultado a casos de implantação dos modelos citados ou de melhoria de processos utilizando os modelos. O terceiro conjunto de termos limita a publicações que mencionam fatores ou estratégias da implantação ou melhoria de processos relatada. Este terceiro conjunto de termos foi o mesmo utilizado por Montoni (2010) para o mapeamento de fatores críticos em melhoria de processo de software, tendo, dessa forma, sido validado naquele contexto.

A seleção das publicações foi realizada em três etapas:

(1) Seleção e catalogação preliminar das publicações coletadas nas fontes a partir da expressão de busca;

(2) Primeiro filtro de seleção das publicações relevantes, por meio de análise do resumo (abstract) e aplicando o critério de seleção "CS1 - possuir informações sobre fatores que exercem influência no sucesso ou fracasso da melhoria de processos de serviços de TI";

(3) Segundo filtro de seleção das publicações relevantes, por meio da leitura completa dos artigos e aplicando os critérios de seleção " $C S 2$ - possuir evidência de que os fatores apresentados foram originados a partir de estudos e pesquisas ou descrições de casos de iniciativas de melhoria de processos de serviço" e "CS3 apresentar informações sobre fatores que exercem influência nas iniciativas de melhoria de processos de serviço de TI, e não na execução dos processos em si”. 
Foi definido ainda um critério de inclusão para adicionar eventuais publicações relevantes não coletadas por meio da expressão de busca, mas referenciadas em outro artigo selecionado. O seguinte critério de inclusão foi aplicado: " $C I 1$ - ser referenciada em alguma publicação escolhida ao fim das três etapas de seleção e atender aos critérios da segunda e terceira etapas de seleção (CS1, CS2 e CS3)".

Para as publicações consideradas relevantes, os seguintes dados foram extraídos: dados da publicação (título, autor(es), data da publicação, fonte de publicação), resumo da publicação, listagem dos fatores de influência positiva nas iniciativas de melhoria de processos de serviços de TI, listagem dos fatores de influência negativa nas iniciativas de melhoria de processos de serviços de TI e origem dos fatores identificados.

O método de análise teve como base os procedimentos do método Grounded Theory (GT ou Teoria Fundamentada em Dados). GT é um método científico que coleta e analisa os dados para gerar, elaborar e validar teorias substantivas sobre fenômenos ou processos sociais (Bandeira de Mello e Cunha, 2003). Uma teoria é um conjunto de conceitos relacionados por sentenças de relacionamento e que, juntos, constituem um esquema que pode explicar ou predizer um fenônemo (Strauss e Corbin, 1998). As teorias substantivas são teorias que emergem dos dados e são específicas para determinado grupo ou situação, não generalizando além da sua área substantiva (Bandeira de Mello e Cunha, 2003). Strauss e Corbin (1998) propõem os seguintes tipos de procedimentos de codificação para o método Grounded Theory:

- Codificação aberta (Open coding): Processo analítico em que conceitos e categorias são identificados e suas propriedades e dimensões são descobertas nos dados;

- Codificação axial (Axial coding): Processo de relacionamento de categorias e subcategorias para formar explicações mais precisas e completas sobre o fenômeno;

- Codificação seletiva (Selective coding): Processo de integrar e refinar a teoria, organizando as categorias em torno de um conceito central.

Os dados coletados nas publicações selecionadas foram analisados quantitativa e qualitativamente. A análise qualitativa resultou em grafos gerados por meio de Grounded Theory e da discussão com relação às questões de pesquisa. A análise quantitativa resultou em: uma lista de tipos de achados de fatores de influência positiva e o total de ocorrências relacionadas; uma lista de tipos de achados de fatores de influência negativa e o total de ocorrências relacionadas; uma lista de propriedades de fatores críticos de sucesso e o total de ocorrências relacionadas; uma lista de fatores críticos de sucesso e o total de ocorrências relacionadas.

\section{Resultados do Mapeamento Sistemático}

\subsection{Execução da pesquisa}

Após o estabelecimento do protocolo, a pesquisa foi executada em Fevereiro de 2013. Na primeira etapa de seleção das publicações, a expressão de busca foi executada nas máquinas de buscas Compendex e Scopus e verificada nos arquivos das conferências nacionais SBQS e WAMPS. Na Compendex, 53 publicações foram obtidas e na Scopus foram retornadas 43 , sendo 33 comuns com a Compendex. Nas conferências nacionais, nenhum artigo que atendesse à expressão de busca foi encontrado.

$\mathrm{Na}$ segunda etapa de seleção das publicações, o resumo (abstract) de cada publicação foi lido. Seguindo o critério de seleção CS1, foram selecionadas dez publicações. 
$\mathrm{Na}$ terceira etapa, não foi possível acessar uma das publicações, pois ela não estava disponível para download, e nove foram lidas completamente. Uma publicação não atendia ao critério de seleção $C S 3$, pois apenas apresentava fatores que influenciavam a execução do processo de gerenciamento de incidentes. Outras três publicações não atendiam ao critério de seleção $C S 2$, pois derivavam fatores a partir dos controles do framework COBIT ou de revisão da literatura, ou não apresentavam informações sobre o estudo que originou os fatores.

Além da seleção dos artigos retornados com a execução da busca, uma publicação foi adicionada, pois atendia ao critério de inclusão CII. Com isso, seis publicações ao todo foram consideradas relevantes à pesquisa.

A identificação de fatores críticos nas publicações que os derivavam a partir de pesquisas e estudos foi direta. Nas publicações que descrevem casos de iniciativas, além dos fatores apontados explicitamente, foram identificados outros fatores a partir do conteúdo da descrição dos casos. Além disso, nem sempre as publicações apresentam uma seção específica para os fatores e, assim, seções de discussões de lições aprendidas e de considerações finais/conclusões também são fontes dessas informações.

\subsection{Análise dos resultados da pesquisa}

Com as informações obtidas nas publicações relevantes ao estudo, é possível responder às questões de pesquisa definidas. As publicações foram inicialmente analisadas com a aplicação do procedimento de codificação aberta do método Grounded Theory. Os trechos dos artigos que indicavam achados relacionados a fatores críticos de sucesso ou de fracasso foram verificados e buscou-se identificar similaridades e diferenças entre esses dados. A partir dessa análise, os achados foram classificados de acordo com o tipo de influência que exercem nas iniciativas de melhoria. Essas categorias foram denominadas "Tipos de achados de fatores de influência positiva" e "Tipos de achados de fatores de influência negativa" e somam 31 no total.

Em seguida, foi executado o procedimento de codificação axial, em duas iterações, para estabelecer categorias mais abstratas dos códigos de tipos de achados. $\mathrm{Na}$ primeira iteração, os códigos de tipos de achados foram agrupados em 22 categorias denominadas "Propriedades de fatores críticos de sucesso". Em uma iniciativa de melhoria, a ausência de uma propriedade representa um fator de influência negativa, enquanto a presença da propriedade representa um fator de influência positiva (Montoni, 2010). Na segunda iteração, as categorias de propriedades foram agregadas em um nível mais abstrato, resultando em 8 categorias de "Fatores crítico de sucesso". São eles: [F01] Processos; [F02] Apoio, comprometimento e envolvimento; [F03] Recursos internos e externos; [F04] Competências dos envolvidos no projeto; [F05] Estrutura e cultura da organização; [F06] Estratégia de implementação do projeto de melhoria; [F07] Colaboração, comunicação e conciliação das partes envolvidas; [F08] Estratégias para promoção do projeto e divulgação dos resultados.

Para estabelecer as relações entre as categorias identificadas, foi elaborado um grafo para cada fator crítico de sucesso. O conector "é propriedade de" foi utilizado para relacionar os códigos de categorias de propriedades de fatores com os códigos de categorias de fatores críticos de sucesso. Os conectores "é uma evidência de presença de" e "é uma evidência de ausência de" foram utilizados para relacionar os códigos de categorias de tipos de achados com os códigos de categorias de propriedades de fatores e mos- 
tram, respectivamente, uma variação positiva e uma variação negativa da presença de um fator. Os códigos apresentados nos grafos são seguidos de dois números que representam o grau de fundamentação (groundness) e o de densidade teórica (density). $\mathrm{O}$ grau de fundamentação representa o número de passagens de texto associadas ao código, enquanto o grau de densidade teórica indica o número de relacionamentos do código com outros códigos. As Figuras 1, 2 e 3 apresentam, respectivamente, os grafos com as categorias e relações associadas aos fatores [F01] Processos, [F02] Apoio, comprometimento e envolvimento e [F03] Recursos internos e externos.

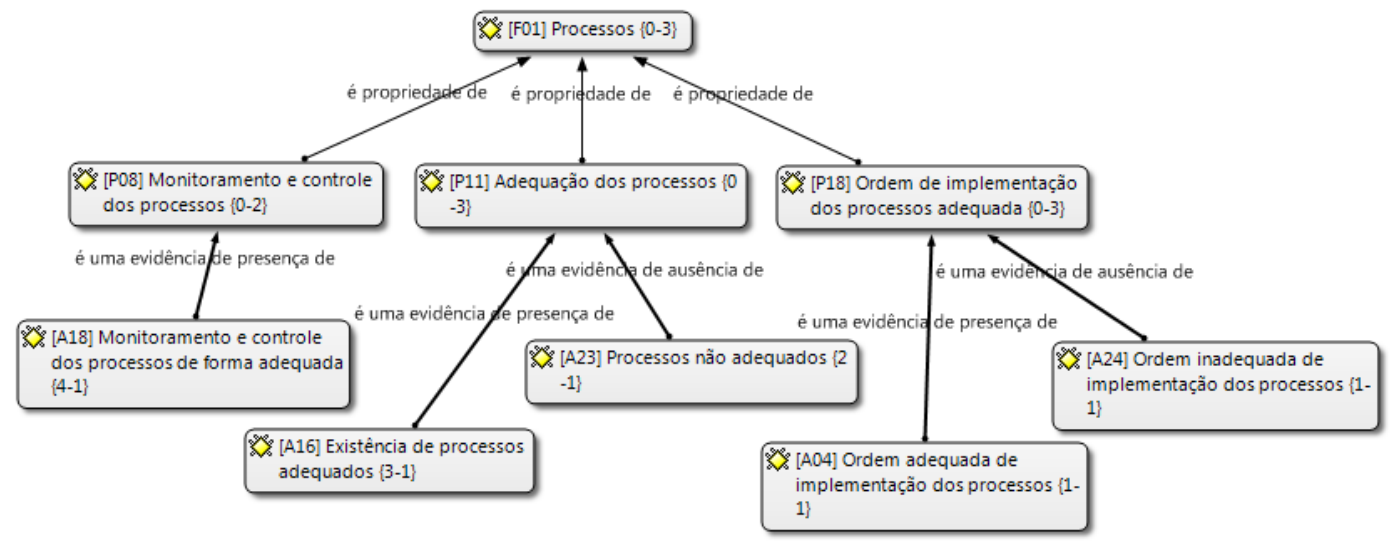

Figura 1 - Categorias e associações relacionadas a "[F01] Processos"

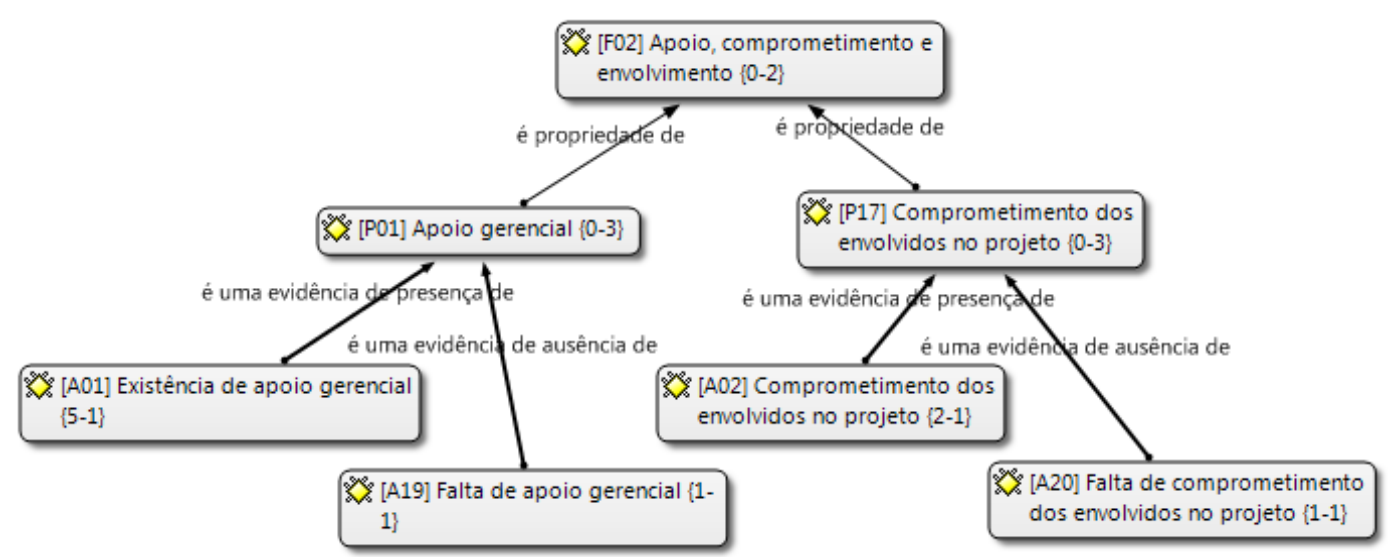

Figura 2 - Categorias e associações relacionadas a "[F02] Apoio, comprometimento e envolvimento"

Neste trabalho não foi necessária a execução da codificação seletiva, pois foi possível compreender os fatores críticos de sucesso após as codificações aberta e axial. Além disso, para execução da codificação seletiva, as categorias e suas relações precisam ser validadas até que se atinja o ponto da saturação teórica, quando ganhos marginais no poder explicativo da teoria para mais evidências coletadas é aproximadamente nulo (Bandeira de Mello e Cunha, 2003).

Após a identificação de todas as categorias, foram contabilizadas as ocorrências delas nas publicações, visando identificar as categorias mais citadas. A Tabela 1 apresenta a ocorrência de alguns tipos de achados de fatores de influência positiva, enquanto a Tabela 2 contabiliza alguns tipos de achados de influência negativa. Na Tabela 3 são apresentadas as ocorrências de todas as propriedades de fatores críticos que agrupam as 
71 ocorrências de achados nas publicações. Por fim, a Tabela 4 contabiliza as ocorrências dos fatores críticos de sucesso que agregam as propriedades de fatores.

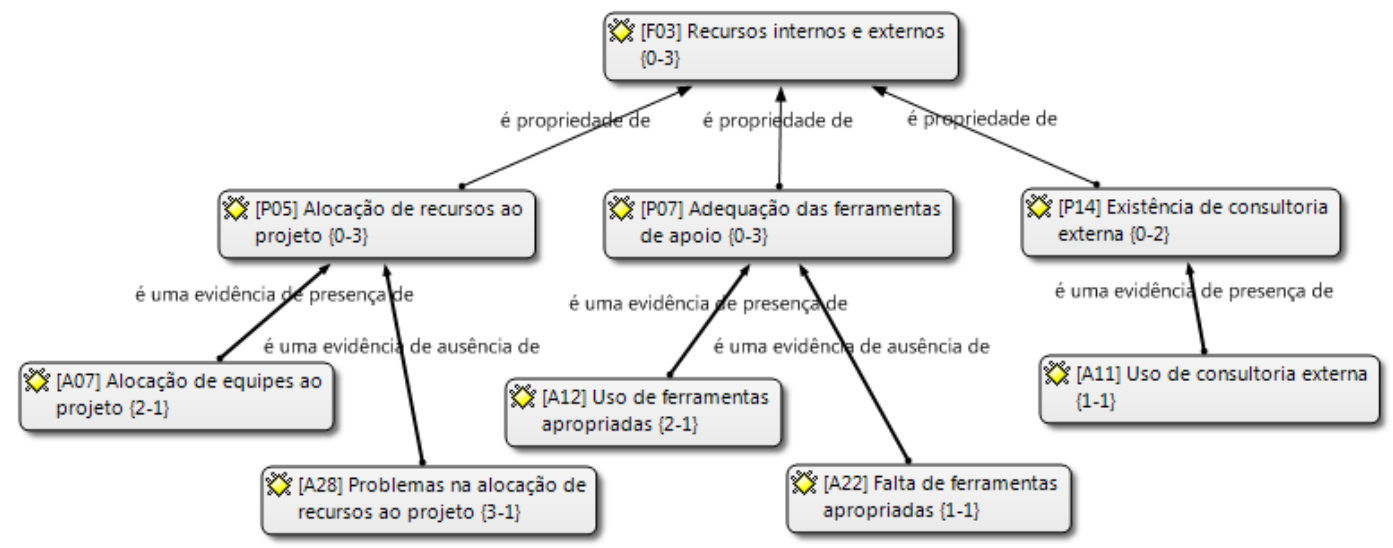

Figura 3 - Categorias e associações relacionadas a "[F03] Recursos internos e externos" Tabela 1 - Ocorrências de alguns Tipos de Achados de Fatores de Influência Positiva

\begin{tabular}{|c|c|c|c|c|c|c|}
\hline $\begin{array}{c}\text { Tipos de achados } \\
\text { de fatores de } \\
\text { influência } \\
\text { positiva }\end{array}$ & $\begin{array}{l}\text { Cater-Steel et } \\
\text { al. }(2006)\end{array}$ & $\begin{array}{l}\text { Hochstein et al. } \\
\qquad(2005)\end{array}$ & $\begin{array}{c}\text { Pollard e } \\
\text { Cater-Steel } \\
\text { (2009) }\end{array}$ & $\begin{array}{l}\text { Tan et al. } \\
\text { (2009) }\end{array}$ & $\begin{array}{l}\text { Tan et al. } \\
\text { (2007) }\end{array}$ & $\begin{array}{l}\text { Total de } \\
\text { ocorrên- } \\
\text { cias }\end{array}$ \\
\hline $\begin{array}{l}\text { [A06] Envolvi- } \\
\text { dos no projeto } \\
\text { com experiência } \\
\text { necessária }\end{array}$ & $\begin{array}{c}\text { Treinamento de } \\
\text { base e desenvol- } \\
\text { vimento de } \\
\text { pessoal }\end{array}$ & $\begin{array}{c}\text { Entendimento para } \\
\text { processos orientados } \\
\text { a serviço / Imple- } \\
\text { mentar treinamento } \\
\text { em larga escala / } \\
\text { Fomentar o desen- } \\
\text { volvimento de pes- } \\
\text { soal em larga escala } \\
\end{array}$ & $\begin{array}{l}\text { Treinamento } \\
\text { e conscienti- } \\
\text { zação de } \\
\text { pessoal }\end{array}$ & & Treinamento & 6 \\
\hline $\begin{array}{l}{[\text { A01] Existência }} \\
\text { de apoio gerenci- } \\
\text { al }\end{array}$ & \begin{tabular}{|c|} 
Apoio da gerên- \\
cia para exercer \\
pressão pela \\
mudança \\
\end{tabular} & $\begin{array}{l}\text { Apoio gerencial para } \\
\text { exercer pressão }\end{array}$ & $\begin{array}{c}\text { Apoio da alta } \\
\text { gerência }\end{array}$ & $\begin{array}{l}\text { Apoio da alta } \\
\text { gerência }\end{array}$ & $\begin{array}{l}\text { Compromisso } \\
\text { da alta admi- } \\
\text { nistração }\end{array}$ & 5 \\
\hline $\begin{array}{l}\text { [A05] Promoção } \\
\text { do projeto }\end{array}$ & $\begin{array}{l}\text { Campanhas de } \\
\text { marketing para } \\
\text { aceitação e } \\
\text { entendimento }\end{array}$ & $\begin{array}{c}\text { Exibição de ganhos } \\
\text { rápidos para de- } \\
\text { monstrar utilidade da } \\
\text { gestão de serviços / } \\
\text { Campanhas de mar- } \\
\text { keting para aceitação } \\
\text { e entendimento } \\
\end{array}$ & & $\begin{array}{l}\text { Campeão de } \\
\text { projeto (Pro- } \\
\text { ject Champi- } \\
\text { on - gerente } \\
\text { sênior que } \\
\text { defende o } \\
\text { projeto) } \\
\end{array}$ & & 4 \\
\hline $\begin{array}{l}\text { A18] Monito- } \\
\text { ramento e contro- } \\
\text { le dos processos } \\
\text { de forma ade- } \\
\text { quada }\end{array}$ & $\begin{array}{c}\text { Melhoria contí- } \\
\text { nua para garantir } \\
\text { sustentabilidade } \\
\text { do sucesso }\end{array}$ & $\begin{array}{l}\text { Esforço para melho- } \\
\text { ria contínua para } \\
\text { sustentabilidade do } \\
\text { sucesso do projeto }\end{array}$ & & & $\begin{array}{c}\text { Metodologia } \\
\text { de processo / } \\
\text { Desempenho } \\
\text { de processo }\end{array}$ & 4 \\
\hline $\begin{array}{l}\text { [A10] Cultura } \\
\text { favorável ao } \\
\text { projeto }\end{array}$ & $\begin{array}{c}\text { Mudança cultu- } \\
\text { ral da equipe de } \\
\text { TI, usuários e } \\
\text { clientes }\end{array}$ & & $\begin{array}{c}\text { Criação de } \\
\text { cultura ade- } \\
\text { quada ao ITIL }\end{array}$ & $\begin{array}{c}\text { Mudança na } \\
\text { cultura orga- } \\
\text { nizacional }\end{array}$ & & 3 \\
\hline $\begin{array}{l}\text { [A16] Existência } \\
\text { de processos } \\
\text { adequados }\end{array}$ & $\begin{array}{c}\text { Reengenharia } \\
\text { dos processos de } \\
\text { negócio }\end{array}$ & & $\begin{array}{l}\text { Definição de } \\
\text { processos } \\
\text { antes de fer- } \\
\text { ramentas }\end{array}$ & & $\begin{array}{l}\text { Metodologia } \\
\text { de processo }\end{array}$ & 3 \\
\hline
\end{tabular}


Tabela 2 - Ocorrências de alguns Tipos de Achados de Fatores de Influência Negativa

\begin{tabular}{|c|c|c|c|c|}
\hline $\begin{array}{c}\text { Tipos de achados } \\
\text { de fatores de influ- } \\
\text { ência negativa } \\
\end{array}$ & $\begin{array}{l}\text { Cater-Steel et al. } \\
\quad(2006)\end{array}$ & $\begin{array}{l}\text { Hochstein et al. } \\
\text { (2005) }\end{array}$ & Wan et al. (2008) & $\begin{array}{c}\text { Total de } \\
\text { ocorrências }\end{array}$ \\
\hline $\begin{array}{l}\text { [A26] Problemas } \\
\text { no entendimento e } \\
\text { dimensão do proje- } \\
\text { to }\end{array}$ & & & $\begin{array}{l}\text { Objetivos do projeto não são claros / } \\
\text { Análise da demanda de negócio não é } \\
\text { suficiente / Mudanças na demanda do } \\
\text { cliente com frequência/ Escala do } \\
\text { projeto é muito grande (o que aumen- } \\
\text { ta a complexidade gerencial) }\end{array}$ & 4 \\
\hline $\begin{array}{l}\text { [A21] Resistência } \\
\text { a mudanças }\end{array}$ & $\begin{array}{c}\text { Resistência a } \\
\text { mudanças culturais }\end{array}$ & $\begin{array}{c}\text { Falta de aceitação / } \\
\text { Falta de entendi- } \\
\text { mento da necessi- } \\
\text { dade de novos } \\
\text { processos } \\
\end{array}$ & & 3 \\
\hline $\begin{array}{l}\text { [A28] Problemas } \\
\text { na alocação de } \\
\text { recursos ao projeto }\end{array}$ & & & $\begin{array}{c}\text { Saída de membros capacitados da } \\
\text { equipe / Recursos necessários não são } \\
\text { suficientes / Definição de responsabi- } \\
\text { lidades vaga entre as equipes dos dois } \\
\text { lados (cliente e fornecedor) }\end{array}$ & 3 \\
\hline $\begin{array}{l}\text { [A29] Problemas } \\
\text { na gestão da orga- } \\
\text { nização }\end{array}$ & & & $\begin{array}{c}\text { Seniores são imprudentes ao tomar } \\
\text { decisões / Estratégia de negócio da } \\
\text { empresa é vaga / Planejamento e } \\
\text { projeto da infraestrutura de TI não são } \\
\text { razoáveis }\end{array}$ & 3 \\
\hline
\end{tabular}

Tabela 3 - Ocorrências de Propriedades de Fatores Críticos de Sucesso

\begin{tabular}{|l|c|c|}
\hline \multicolumn{1}{|c|}{ Propriedades de Fatores Críticos de Sucesso } & $\begin{array}{c}\text { Total de } \\
\text { ocorrências }\end{array}$ & $\begin{array}{c}\text { Publicações em que foram } \\
\text { identificadas * }\end{array}$ \\
\hline [P01] Apoio gerencial & 6 & $1,2,3,4,5$ \\
\hline [P02] Experiência e competência dos envolvidos no projeto & 8 & $1,2,3,5,6$ \\
\hline [P03] Gerência adequada da condução do projeto & 2 & 4,5 \\
\hline [P04] Promoção do projeto & 4 & $1,2,4$ \\
\hline [P05] Alocação de recursos ao projeto & 5 & $1,2,6$ \\
\hline [P06] Cultura favorável ao projeto & 6 & $1,2,3,4$ \\
\hline [P07] Adequação de ferramentas de apoio & 3 & $1,3,5$ \\
\hline [P08] Monitoramento e controle dos processos & 4 & $1,2,5$ \\
\hline [P09] Colaboração e comunicação na organização & 3 & 3,6 \\
\hline [P10] Foco no cliente & 2 & 3,5 \\
\hline [P11] Adequação dos processos & 5 & $1,3,5,6$ \\
\hline [P12] Relacionamento com fornecedores e consultores & 2 & 4,5 \\
\hline [P13] Divulgação dos resultados & 2 & 1,2 \\
\hline [P14] Existência de consultoria externa & 1 & 3 \\
\hline [P15] Gerência adequada de benefícios & 2 & 4,5 \\
\hline [P16] Gerência adequada de mudanças & 1 & 5 \\
\hline [P17] Comprometimento dos envolvidos no projeto & 3 & $1,2,6$ \\
\hline [P18] Ordem de implementação dos processos adequada & 2 & 1,6 \\
\hline [P19] Entendimento e dimensão do projeto adequados & 4 & 6 \\
\hline [P20] Gerência adequada da organização & 3 & 6 \\
\hline [P21] Acordo entre as partes envolvidas & 2 & 6 \\
\hline [P22] Adequação do framework de melhoria ao projeto & 1 & -- \\
\hline & $\mathbf{7 1}$ & 2 \\
\hline
\end{tabular}

* [1] Cater-Steel et al. (2006); [2] Hochstein et al. (2005); [3] Pollard e Cater-Steel (2009); [4] Tan et al. (2009); [5] Tan et al. (2007); [6] Wan et al. (2008) 
Tabela 4 - Ocorrências de Fatores Críticos de Sucesso

\begin{tabular}{|l|c|c|}
\hline \multicolumn{1}{|c|}{ Fatores Críticos de Sucesso } & $\begin{array}{c}\text { Total de } \\
\text { ocorrências }\end{array}$ & $\begin{array}{c}\text { Propriedades de Fatores } \\
\text { Críticos de Sucesso } \\
\text { relacionadas }\end{array}$ \\
\hline [F01] Processos & 11 & {$[\mathrm{P} 08],[\mathrm{P} 11],[\mathrm{P} 18]$} \\
\hline [F06] Estratégia de implementação do projeto de melhoria & 10 & {$[\mathrm{P} 03],[\mathrm{P} 15],[\mathrm{P} 16]$,} \\
\hline [F02] Apoio, comprometimento e envolvimento & 9 & {$[\mathrm{P} 01],[\mathrm{P} 17]$} \\
\hline [F03] Recursos internos e externos & 9 & {$[\mathrm{P} 05],[\mathrm{P} 07],[\mathrm{P} 14]$} \\
\hline [F07] Colaboração, comunicação e conciliação das partes envolvi- & 9 & {$[\mathrm{P} 09],[\mathrm{P} 10],[\mathrm{P} 12],[\mathrm{P} 21]$} \\
\hline [F05] Estrutura e cultura da organização & 9 & {$[\mathrm{P} 06],[\mathrm{P} 20]$} \\
\hline [F04] Competências dos envolvidos no projeto & 8 & {$[\mathrm{P} 02]$} \\
\hline $\begin{array}{l}\text { [F08] Estratégias para promoção do projeto e divulgação dos resul- } \\
\text { tados }\end{array}$ & 6 & {$[\mathrm{P} 04],[\mathrm{P} 13]$} \\
\hline \multicolumn{1}{|c|}{ Total } & $\mathbf{7 1}$ & - \\
\hline
\end{tabular}

\section{Comparação com Fatores Críticos em Melhoria de Processos de Software}

Montoni (2010) apresenta um estudo de mapeamento sistemático semelhante para identificação de fatores críticos, porém com foco em iniciativas de melhoria de processos de software. Em seu trabalho, a partir das publicações relevantes analisadas, também foram identificados tipos de achados de influência positiva e de influência negativa, propriedades de fatores e fatores críticos de sucesso. Doze fatores críticos foram indicados e analisados em termos de quantidade total de ocorrências relacionadas. Os fatores "Processos", "Apoio, comprometimento e envolvimento" e "Competências dos membros da organização" representam pouco menos 50\% das ocorrências identificadas e foram considerados mais críticos para alcançar o sucesso de iniciativas de melhoria de processo de software. Já o conjunto seguinte de fatores foi considerado um pouco menos crítico por apresentar um número médio de ocorrências: "Estratégia de implementação de melhoria de processo de software", "Recursos", "Conscientização dos benefícios da implementação da melhoria dos processos", "Estrutura da organização", "Conciliação de interesses" e "Política de reconhecimento à colaboração na melhoria dos processos". Por fim, os fatores considerados de menor influência foram "Respeito da consultoria pelos membros da organização", "Aceitação a mudanças" e "Motivação e satisfação dos membros da organização". Além do mapeamento sistemático, Montoni (2011) também realizou um survey com consultores e membros de organizações de software para identificar fatores críticos de sucesso. O resultado desse survey não foi examinado neste trabalho.

Analisando os fatores críticos identificados para melhoria de processos de software em relação aos fatores para processos de serviços, algumas semelhanças e diferenças foram percebidas. Os fatores "Processos", "Apoio, comprometimento e envolvimento" e "Competências dos envolvidos no projeto"/"Competências dos membros da organização" aparecem nos dois estudos. No estudo de Montoni (2010), os três fatores são considerados de maior importância devido ao total de ocorrências superior em relação a outros fatores. No presente estudo, em termos de total de ocorrências, apenas o fator "Processos" também seria considerado de maior importância, enquanto os outros seriam, respectivamente, de média e baixa importância. Porém, considerando a aparição em todas as publicações analisadas neste estudo, o fator "Apoio, comprometimento e envolvimento" também poderia ser considerado mais crítico. Um ponto diferente é que, no presente estudo, propriedades que abrangem competências dos membros da organização que implementa a melhoria e dos membros da consultoria externa foram agrupados em um mesmo fator. Já na pesquisa de Montoni (2010), a competência da consultoria ex- 
terna foi agrupada no fator "Respeito da consultoria pelos membros da organização" que compreende também o bom relacionamento e confiança entre a organização e a consultoria. Este fator não foi estruturado no presente estudo e as propriedades relativas a relacionamento entre partes foram agrupadas no fator "Colaboração, comunicação e conciliação das partes envolvidas". O fator "Motivação e satisfação dos membros da organização", indicado no trabalho de Montoni (2010), também não foi estruturado nesta pesquisa, pois só foram verificadas propriedades mais gerais relativas ao comprometimento do pessoal.

Neste trabalho, o fator "Recursos internos e externos" foi considerado de média importância devido ao número total de ocorrências e compreende também o uso de consultores externos no projeto. No estudo de Montoni (2010), o fator "Recursos" foi igualmente avaliado como um fator de média criticidade, mas as propriedades relacionadas ao uso de consultorias ficaram agrupadas no fator "Competências dos membros da organização" avaliado com alta importância. Além disso, no presente estudo não foi identificado nenhum tipo de achado específico para recursos de hardware. Já para processos de software, esse item foi percebido no fator "Recursos".

Em ambos os trabalhos foi estruturado um fator que compreende atividades para a gestão da implementação das melhorias como a gestão de um projeto. $\mathrm{O}$ fator definido por Montoni (2010), "Estratégia de implementação de melhoria de processo de software", foi considerado de média influência. Já neste estudo, o fator "Estratégia de implementação do projeto de melhoria" foi indicado como um fator de maior influência devido às suas ocorrências. Nas duas pesquisas também foram definidos fatores que abrangessem a divulgação dos resultados obtidos e a promoção do projeto de melhoria para conscientização dos envolvidos. O fator "Estratégias para promoção do projeto e divulgação dos resultados" foi estruturado neste trabalho e considerado de baixa criticidade. Montoni (2010) indica o fator "Conscientização dos benefícios da implementação da melhoria dos processos" com influência média.

O fator "Estrutura e cultura da organização" foi definido no presente estudo como uma questão de média influência e compreende propriedades de gestão, estruturação, planejamento e cultura da organização que implementa o projeto de melhoria. Montoni (2010) apresentou os fatores "Estrutura da organização" e "Aceitação a mudanças", respectivamente de média e baixa influência, para contemplar preocupações de contexto semelhante (com exceção da cultura em metodologias e processos que foi considerada pelo autor no fator "Processos").

Por fim, neste trabalho, foi estruturado o fator "Colaboração, comunicação e conciliação das partes envolvidas" com criticidade média. Os fatores "Conciliação de interesses" e "Política de reconhecimento à colaboração na melhoria dos processos", definidos por Montoni (2010) e também de influência média, compreendem questões similares (exceto pelo relacionamento com a consultoria externa que foi agrupado pelo autor no fator "Respeito da consultoria pelos membros da organização").

\section{Considerações finais}

Este trabalho apresentou um estudo sobre fatores críticos de sucesso em iniciativas de melhoria de processos de serviços de TI, por meio de mapeamento sistemático da literatura e aplicação de procedimentos do método Grounded Theory. A análise desses fatores críticos pode auxiliar as organizações a desenvolver estratégias para a implantação 
de melhorias em processos de serviços de TI, atentando para características que podem direcionar o sucesso das iniciativas.

Alguns fatores foram considerados mais relevantes e destacam a importância de: processos adequados, monitorados, controlados e implementados em ordem adequada; apoio gerencial e comprometimento dos envolvidos no projeto; e estratégias de implementação do projeto de melhoria, envolvendo a execução e governança do projeto, a gestão de benefícios e mudanças, o entendimento e dimensão do projeto e a adequação do framework de melhoria utilizado.

Outros fatores de menor influência também foram identificados e englobam: alocação de recursos - equipes, consultoria externa e ferramentas - ao projeto; experiência e competência dos envolvidos no projeto; estrutura e cultura da organização (estratégia de negócio, planejamento, cultura favorável ao projeto de melhoria); colaboração, comunicação e conciliação entre as equipes, cliente, consultoria externa e fornecedores; e estratégias para promoção e aceitação do projeto e divulgação de seus resultados.

Os fatores identificados também foram comparados a fatores críticos para iniciativas de melhoria de processos de software. Apesar de algumas diferenças em relação do grau de importância, muitas semelhanças em relação ao contexto compreendido pelos fatores foram percebidas e revelam preocupações similares para os dois tipos de iniciativas de melhoria. Porém, ainda existem poucos relatos sobre fatores de influência em melhoria de processos de serviço de TI. Os modelos CMMI-SVC e MPS-SV são recentes (lançados, respectivamente, em 2009 e 2012) e sua adoção com o tempo pode auxiliar a compreensão da implementação de melhorias para este tipo de processos.

Como um procedimento de qualidade da pesquisa, outro pesquisador com experiência na condução e revisão de estudos similares avaliou todo o protocolo e a sua execução. Foram realizados ajustes e chegou-se a um consenso em relação às análises realizadas. Por outro lado, existem ameaças à validade do estudo. Há publicações que descrevem de maneira breve os fatores identificados ou apenas indicam seu nome. $\mathrm{O}$ entendimento do que um fator compreende pode influenciar a decisão de qual categoria agrupá-lo. Além disso, podem existir publicações relevantes que não estão indexadas nas fontes de dados selecionadas ou que não apresentem em seu resumo (abstract) os termos considerados importantes para o estudo e utilizados para compor a expressão de busca.

Para complementar os resultados obtidos, um trabalho futuro é a utilização de procedimentos de Snowballing para a identificação de artigos relevantes que citam as publicações selecionadas no mapeamento ou que estão em sua lista de referência, e que atendem a expressão de busca definida. Outro desdobramento deste estudo é a investigação da percepção dos fatores identificados por organizações que utilizam os modelos de processos de serviços de TI, a fim de confirmar os achados e verificar sua aplicação no cenário nacional.

\section{Referências}

Bandeira de Mello, R., Cunha, C., 2003, "Operacionalizando o método da Grounded Theory nas Pesquisas em Estratégia: técnicas e procedimentos de análise com apoio do software ATLAS/TI". Encontro de Estudos em Estratégia. Curitiba, Brasil. 
Barreto, A. O. S., Rocha, A. R., 2009, "Definição e Monitoração de Objetivos de Software Alinhados ao Planejamento Estratégico". Simpósio Brasileiro de Qualidade de Software, SBQS.

Cater-Steel, A., Toleman, M., Tan, W.-G., 2006, "Transforming IT service management- The ITIL impact". Australasian Conference on Information Systems ACIS.

Cartlidge, A., Hanna, A., Rudd, C., Macfarlane, I., Windebank, J., Rance, S. (2007) “An introductory overview of ITIL v3".IT Service Management Forum. ISBN: 9780955124587. Disponível em: http://www.best-managementpractice.com/gempdf/itSMF_An_Introductory_Overview_of_ITIL_V3.pdf

Hochstein, A., Tamm, G., Brenner, W., 2005, "Service-oriented IT management: benefit, cost and success factors". European Conference of Information Systems, ECIS.

ISO - International Standard Organization (2009) "ISO/IEC TR 20.000-3: Information Technology - Service Management - Part 3: Guidance on scope definition and applicability of ISO/IEC 20.000-1”. Suíça.

ISO - International Standard Organization (2010a) "ISO/IEC TR 20.000-4: Information Technology - Service Management - Part 4: Process reference model". Suíça.

ISO - International Standard Organization (2010b) "ISO/IEC TR 20.000-5: Information Technology - Service Management - Part 5: Examplar implementation plan for ISO/IEC 20.000-1". Suíça.

ISO - International Standard Organization (2011) "ISO/IEC 20.000-1: Information Technology - Service Management - Part 1: Service management system requirements". Suíça.

ISO - International Standard Organization (2012) "ISO/IEC 20.000-2: Information Technology - Service Management - Part 2: Code of practice”. Suíça.

ITGI - IT Governance Institute (2007) "COBIT 4.1 - Control Objectives Management Guidelines Maturity Models”. Rolling Meadows, IL - USA. Disponível em: http://www.isaca.org/Knowledge-Center/cobit/Documents/cobit41portuguese.pdf

Ghayekhloo, S., Sedighi, M., Nassiri, R., Latif Shabgahi, G., Tirkolaei, H. K. (2009) "Pathology of organizations currently implementing ITIL in developing countries". International Conference on Computer and Electrical Engineering.

Hochstein, A., Tamm, G., Brenner, W., 2005, "Service-oriented IT management: benefit, cost and success factors". European Conference of Information Systems, ECIS.

Jäntti, M. (2010) "Lessons Learnt from the Improvement of Customer Support Processes: A Case Study on Incident Management". In: Lecture Notes in Business Information Processing.

Magalhães, I., Brito, W. (2007) "Gerenciamento de serviços de TI na prática: uma abordagem com base na ITIL". Novatec Editora, São Paulo.

Montoni, M. (2010) "Uma investigação sobre os fatores críticos de sucesso em iniciativas de melhoria de processos de software", 400p. Universidade Federal do Rio de Janeiro - UFRJ, Rio de janeiro. Tese de Doutorado. 
Montoni, M., Rocha, A. R. C. (2011) "Uma Investigação sobre os Fatores Críticos de Sucesso em Iniciativas de Melhoria de Processos de Software". Simpósio Brasileiro de Qualidade de Software, SBQS.

Pollard, C., Cater-Steel, A. (2009) "Justifications, strategies, and critical success factors in successful ITIL implementations in U.S. and Australian companies: An exploratory study". Information Systems Management.

Rockart, J. F. (1979) "Chief executives define their own data needs". Harvard Business Review, 57(2), 81-93.

SEI - Software Engineering Institute (2010) "CMMI for Services (CMU/SEI-2010-TR034)”, Versão 1.3. Pittsburg: Software Engineering Institute. 520 p.

Sharifi, M., Ayat, M., Rahman, A.A., Sahibudin, S. (2008) "Lessons learned in ITIL implementation failure," in: Information Technology, 2008. ITSim 2008, pp. 1 - 4, IEEE.

SOFTEX (2012) Modelo de Referência para Melhoria de Processo de Serviços. Disponível em www.softex.br/mpsbr

Strauss, A., Corbin, J., 1998, "Basics of Qualitative Research: Techniques and Procedures for Developing Grounded Theory". 2 ed. London, SAGE Publications.

Tan, W.-G., Cater-Steel, A., Toleman, M. (2009) "Implementing it service management: A case study focusing on critical success factors". Journal of Computer Information Systems.

Tan, W.-G., Cater-Steel, A., Toleman, M., Seaniger, R. (2007) "Implementing centralised IT service management: Drawing lessons from the public sector". Australasian Conference on Information Systems, ACIS.

Wan, J., Zhu, S., Wang, Y. (2008) "Empirical analysis on risk factors of IT service management project implementation". International Conference on Wireless Communications, Networking and Mobile Computing, WiCOM. 